\title{
The Management Side Of Talent: Causal Implications For The Retention Of Generation Y Employees
}

Liesel Du Plessis, University of Pretoria, South Africa

Nicolene Barkhuizen, University of Pretoria \& North-West University, South Africa

Karel Stanz, University of Pretoria, South Africa

Nico Schutte, North-West University, South Africa

\begin{abstract}
Organisations are facing significant challenges to retain Generation $Y$ employees. Research shows that, once these individuals are employed, they are not likely to remain in that position for very long. Organisations therefore need to find innovative solutions to retain this group of employees. The purpose of this research was to determine the causal relationship between management support towards talent management and the impact thereof on the turnover intentions of Generation Y employees. The Human Capital Index, Perceived Organisational Support Questionnaire, Perceived Organisational Support and Intention to Quit questionnaires were administered among a convenience sample of generation $Y$ employees $(N=135)$. The results showed that Perceived Organisational Support is significantly related to Talent management practices, Perceived Supervisor Support and Intention to Quit. Perceived Supervisor Support is significantly related to Talent management practices and Intention to Quit. Talent management practices are significantly related to intention to quit. Recommendations are made.
\end{abstract}

Keywords: Generation Y; Retention; Talent Management; Organisational Support

\section{INTRODUCTION}

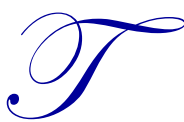
he ability of an organization to build a strong talent pool is central to its success in the $21^{\text {st }}$ Century. As stated by Reindl (2007), the attraction, development and retention of talent through efficient talent management not only promises an edge in the market place, but also an increase in the organization's overall financial performance. However, as Generation Y or Millennials (individuals born after 1980) begin to enter the workforce, organizations are faced with new challenges as they try to find innovative solutions to retain this group of employees. Research shows that, once these individuals are employed, they are not likely to remain in that position for very long (Basset, 2008). Some surveys estimate that members of Generation Y are likely to change their jobs every two years, continually searching for new challenges and experiences (O'Malley, 2006). Generation $\mathrm{Y}$ has, as a result, become known for their professional mobility and constantly increasing turnover in organizations.

This concern forms the basic premise for Generation $\mathrm{Y}$ being the context for the execution of this study. Turnover remains a costly challenge; one which can only be overcome through a genuine interest of employees' perception of the organization, its agents, and its practices (Morgan, 2008). The retention of the best talent amongst Generation Y graduates will present employers with major challenges if organizations are not prepared to change or adapt their human resource policies and consequent talent management practices to accommodate the new generation (Guthridge, et al., 2008; Human Capital Institute (HCI), 2008). One can therefore conclude that an understanding of the relationship between Generation Y employee's perceptions of an organisation's talent management practices, organisational and supervisor support and the impact thereof on their intention to quit, is imperative from a research point of view. 
Extensive research has been conducted on the relationship between an employee's perceived organizational support, perceived supervisor support, and their intention to quit (see Chew \& Wong, 2008; Dawley, Andrews \& Bucklew, 2008; Deconinck \& Johnson, 2009; DeConinck, 2010; Eisenberger, Singlhamber, Vandenberghe, Sucharski, \& Rhoades, 2001; Gentry, Kuhnert, Mondore \& Page, 2007; Jawahar \& Hemmasi, 2006; Loi, Hang-yue $\&$ Foley, 2006; Shanock \& Eisenberger, 2006;). These studies have found a positive correlation between perceived organizational and perceived supervisor support, and a negative relationship between these two constructs and an employee's intent to quit. Only minimal studies to date have investigated the relationship between Human Resource Practices, Perceived Organizational Support, and turnover (Allen et al., 2003; Knight-Turvey \& Neal, 2003). The studies did, however, confirm that supportive Human Resource Practices lead to an increase in the employee's perception of organizational support and a decrease in the employee's intent to leave an organization.

Against this background our main objective is to determine whether there is a causal relationship between perceived talent management practices, perceived organisational and supervisor support and Generation Y's intention to quit the organisation. We anticipate that the investigation of these constructs respectively should provide the organization with some valuable insight on possible factors that relate to employee turnover and provide the organization with the ability to construct a valuable Talent Retention Model for Generation Y. In the next section of the article, the inter relationships between the identified constructs for this research will be discussed.

\section{THEORY AND RESEARCH HYPOTHESES}

\section{Talent Management Practices (Tmp), Perceived Organizational Support (Pos) And Perceived Supervisor Support (Pss)}

The phrase Talent Management (TM) was first used by McKinsey and Company in the late 1990s (Marah $\&$ Leigh-Ann, 2008) and can be defined as "the sum of people's capabilities, experiences, competencies, attitudes and behaviour that can be turned into organizational performance" (Pillay, Subban, \& Qwabe, 2008). Human Capital Institute and Vurv Technology (2008) categorises TM as a "new business science that integrates workforce planning, acquisition, development, mobility and measurement into a strategic discipline." Effective TM is aligned with the organization's mission, values, core objectives, values, and capabilities, and enables leaders of an organization to create a competitive advantage (Human Captial Institute and Vurv Technology, 2008).

The transformation of Human Resource Management to Talent Management is placing demands on HR professionals to redefine the profession to be able to aid organizations to meet the challenges of the $21^{\text {st }}$ century (Human Captial Institute and Vurv Technology, 2008). Research has shown that supportive Human Resource Practices are an antecedent of POS (Allen, et al., 2003). Allen et al. (2003) maintain that organisations are supportive of employees when Human Resource Practices values and cares about employees, is willing to invest in them and recognises employee contributions. One can therefore classify Talent Management as a supportive HR practice.

Research was found that supported the importance of nine respective talent management practices for the application of effective Talent Management in organisations namely Strategy, Talent Review Process, Staffing, Talent Acquisition, Talent Engagement, Talent Development, Talent Deployment, Performance Management and Talent Retention (see Ashton \& Morton, 2005; Bhatnagar, 2008; Cantrell \& Benton, 2007; Cappelli, 2008a; Galagan, 2008; Handfield-Jones, Michaels \& Axelrod, 2001; HCI, 2008; Michaels, 1999; Reindl, 2007; Sharma \& Bhatnagar, 2009; Workforce Management, 2007). Although it has been found that these practices could contribute to effective Talent Management, no studies have yet been conducted to establish empirical evidence that confirms the impact of these practices on employees' intention to leave the organization or on their perception of support from the organization or their supervisor. Research has, however, found that an employee's perception of an organization's dedication to supportive organizational practices is positively related to POS (Allen, et al., 2003). It therefore follows that an employee's perception of the organization's dedication towards TMP should also be positively related to POS.

Hutchison (1997) found that employees' perception of the organization's actions had a direct effect on their perception of support from their supervisors (PSS). Research confirmed the direct positive relationships between 
POS and supportive HR practices such as Talent Management; and POS and PSS (see Allen, et al., 2003; Hutchison, 1997). It can therefore be concluded that, indirectly, a relationship between supportive HR practices such as Talent Management and PSS is probable.

Hypothesis 1: A positive relationship exists between the employee's perception of the organization's TMP and POS.

Hypothesis 2: A positive relationship exists between the employee's perception of the organization's TMP and PSS.

\section{Talent Management Practices and Intention to Quit}

Research has found that supportive HR practices that indicate the organization's willingness to invest in human capital enhance employee retention (Mpofu \& Barkhuizen, 2013). The ability of supportive Talent Management practices to enhance retention, suggests that these practices are likely to decrease an employee's intention to leave an organization (Theron, Barkhuizen \& Du Plessis, 2014). A study by Barkhuizen (2014) further showed that generation $\mathrm{Y}$ in particular regard talent management practices such Talent Development, Talent review processes, Workforce planning, Staffing and Acquisition as more important compared to other generations in workplace. Barkhuizen (2014) found that career development in particular will retain generation Y employees in the workplace.

Hypothesis 3: A negative relationship exists between the employee's perception of the organization's TMP and his/her intention to quit.

\section{Perceived Organizational Support, Talent Management Practices and Intention to Quit}

Employees develop a mindset or a overarching belief about the extent to which their organization values their contributions and cares about their general well-being, which is known as their perception of organizational support (POS) (Eisenberger, et al., 2002). Perceived Organizational Support is also the belief that assistance will be readily available from the organization when help is needed to carry out one's job effectively or to deal with stressful situations (Rhoades \& Eisenberger, 2002). The Social Exchange Theory has often been used to study organizations in an attempt to better understand the reciprocal relationships that develop between employees and the organization (Dawley, et al., 2008). This view suggests that when an employer provides employees with fair treatment and when they value their employees' contributions and well-being, the employees will perceive high levels of support from the organization and, as a result, feel obligated to reciprocate (Dawley, et al., 2008).

Based on these principles, it can be argued that individuals who receive greater support from their organization will be more inclined to return the act of goodwill. The employee's reciprocal act can include higher organizational commitment and loyalty, which results in a decreased intention to quit the organization (Magolego, Barkhuizen \& Lesenyeho, 2013; Mpofu \& Barkhuizen, 2013). Allen et al. (2003) also stated that the inverse is true, where an employee's perception of low organization support may result in an increased intention to quit.

The employee's perception of Human Resource or TMP (an antecedent to POS), become the basis for their perceptions of support from management and supervisors, which forms the foundation of their global perception of the organization's support (Veldman, 2012). Various studies have found that individuals with high POS will be less likely to seek and accept alternative employment (Allen, et al., 2003, Armstrong-Stassen \& Ursel, 2009; Dawley, et al., 2008; Harris, Harris \& Harvey, 2007; Hui, Wong \& Tjosvold, 2007; Jawahar \& Hemmasi, 2006; Loi, et al., 2006; Riggle, Edmondson \& Hansen, 2009). In addition, Allen et al. (2003) has found that POS can act as the mediator of organizational supportive Human Resource Practices and the turnover process, and therefore indirectly of the employee's intention to quit. The presence of POS consequently can be seen as the explanation behind a negative correlation between supportive HR practices and employee turnover.

Hypothesis 4: A negative relationship exists between the employee's perception of the organizational support and his/her intention to quit. 
Hypothesis 5: POS mediates the relationship between perceived TMP and the employee's intention to quit.

\section{Perceived Organizational Support and Perceived Supervisor Support}

Numerous studies have investigated the positive relationship between Perceived Organizational Support and Perceived Supervisor Support, but very few studies have been conducted to investigate the direction of the causality between POS and PSS (Eisenberger, et al, 2002). Research has shown that Perceived Supervisor Support is an antecedent of POS (Allen, et al., 2003; Dawley, et al, 2008; Rhoades \& Eisenberger, 2002; Shanock \& Eisenberger, 2006; Zagenczyk, Scott, Gibney, Murell, \& Thatcher, 2010). The organizational support theory encourages this finding that a positive relationship exists between PSS and POS, where PSS leads to POS (Eisenberger, et al., 2002).

Yoon and Thye (cited in Eisenberger, et al., 2002) suggested that causality might also occur in the reverse direction where POS increases PSS. This has been confirmed by other research studies such as: Hutchison's study (1997) on a Path Model of Perceived Organizational Support, DeConinck's study (2010) on POS, PSS, organizational justice, and trust, and Dawley et al.'s study (2008) on Mentoring, PSS, and POS. These authors argue that the employees' perception that the organization values their contribution and cares about their well-being leads them to believe that supervisors (who act as agents of the organization), are favourably inclined towards them (Eisenberger, et al., 2002). All studies seem to concur that a positive relationship exists between POS and PSS (Dawley, et al, 2008; Shanock \& Eisenbeger, 2006).

Hypothesis 6: A positive relationship exists between the POS and PSS.

\section{Perceived Supervisor Support, Talent Management Practices and Intention to Quit}

Employees develop overarching perceptions about the degree to which supervisors value their contributions and care about their well-being (Eisenberger, et al., 2002). This general belief is called perceived supervisor support (PSS). Supervisors act as agents of the organization and consequently have the ability to act favourably or unfavourably towards employees (Eisenberger, et al., 2002). Employees see this as an indication of the organization's support, which explains the strong correlation between POS and PSS. Employee's satisfaction with their immediate supervisor and their perception of their supervisor's willingness to value and care for them has been shown to reduce voluntary turnover and improve commitment (Dawley, et al., 2008). Moreover management commitment towards talent management in organisations has constantly been related to employees' intention to quit the organisations (Diseko, 2015; Masale, 2015; Mpofu, 2013). Therefore, a logical deduction would be that enhanced perception of supervisor support will decrease the employee's need or intent to leave the organization.

Hypothesis 7: A negative relationship exists between the employee's PSS and his/her intention to quit the organization.

According to Allen et al. (2003), POS acts as mediator of organizational supportive HR Practices and the degree to which employees leave an organization. Since supervisors act as agents for the organization and therefore personify of the organization suggests that PSS can possibly act as an even stronger mediator. It is therefore probable that the presence of PSS can be seen as the explanation behind a negative correlation between supportive HR practices and employee turnover.

Hypothesis 8: PSS mediates the relationship between perceived TMP and the employee's intention to quit.

\section{Integrated Conceptual Model for the Research}

As stipulated by the literature review, research has confirmed a positive correlation between perceived organizational support and perceived supervisor support, and a negative relationship between these two constructs and an employee's intent to quit (Chew \& Wong, 2008; Dawley, et al., 2008; DeConinck, 2010; DeConinck \& Johnson, 2009; Eisenberger, et al., 2002; Gentry, et al., 2007; Jawahar \& Hemmasi, 2006; Loi, et al., 2006; Shanock \& Eisenberger, 2006). Research has furthermore found that supportive HR/TM practices increase POS and 
decreases turnover and presumably the employee's intent to leave (Allen, et al., 2003; Knight-Turvey \& Neal, 2003).

Based on the literature review and the supporting propositions, an integrated conceptual model is proposed where the relationships between the constructs can be investigated as an aim for the study to follow. The proposed direction of the relationship between these constructs is demonstrated in figure 1, with Generation $Y$ serving as a contextual framework for the study.

Figure 1. Integrated conceptual model for this research

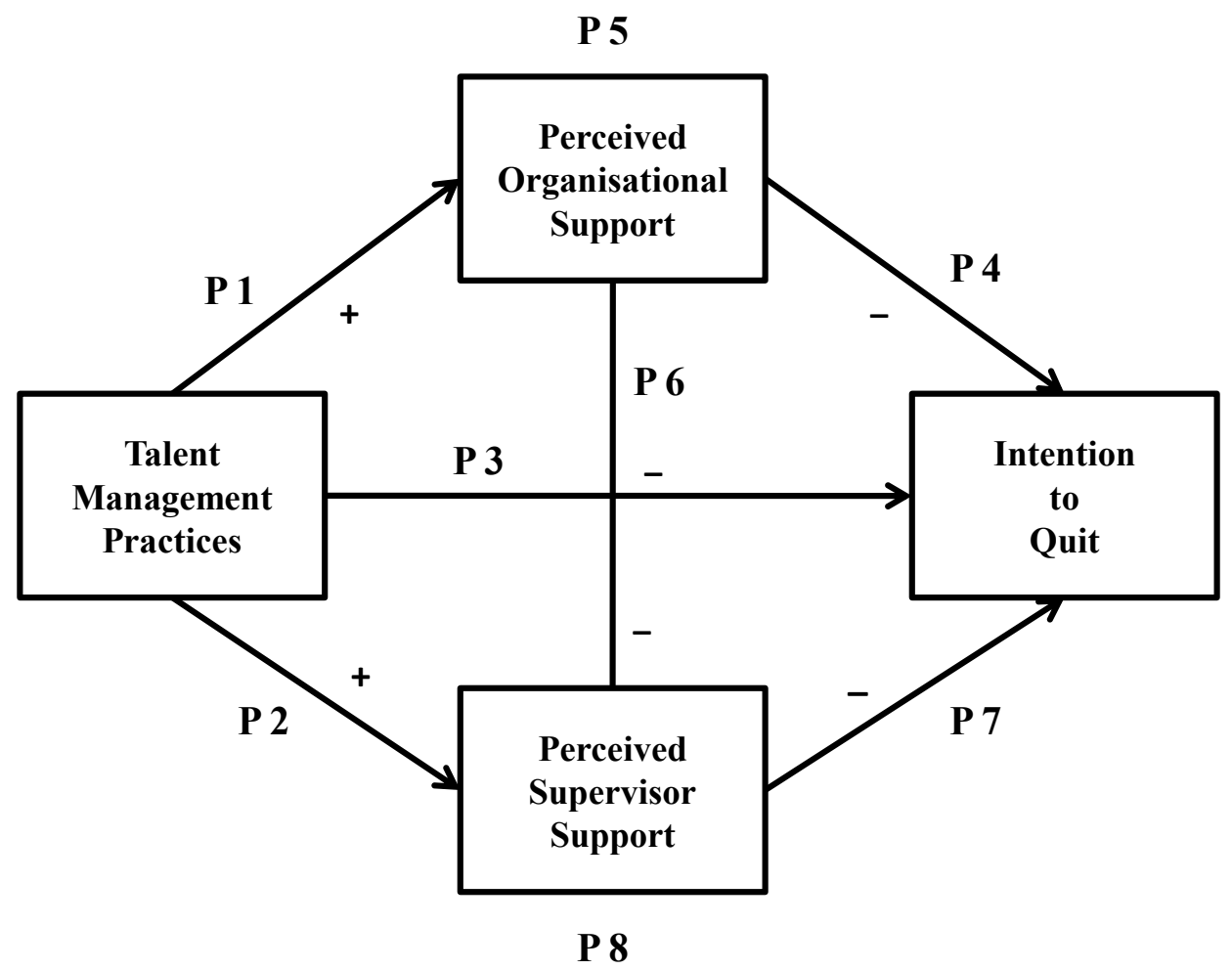

In the next section of the article, the research design will be pointed out and the results of the research showed. The article concludes with an overall discussion of the research results and provides recommendations for managers and future research in terms of perceived TMP, perceived organisational support, perceived supervisor support and intention to quit.

\section{Research Design}

A quantitative research approach was followed. A cross-sectional survey design was used to collect data and attain the research goals. This design is ideally suited to the descriptive and predictive functions associated with correlation research and to assess the interrelationships between the variables in the research (Field, 2009).

\section{Sample}

A convenience sample was taken from Generation $\mathrm{Y}$ employees working in an organization operating within the recruitment industry $(N=135)$. This resulted in a response rate of $30 \%$. Respondents in this sample were primarily female (94.81\%), white (71.85\%), English (42.96\%) and Afrikaans (40\%) speaking and single (54.07\%). Most of the respondents were employed in the production unit (60\%), permanently employed (97.04\%) and employed between 1 and 3 years $(80.74 \%)$ in the organisation. 


\section{Measurements}

The Human Capital Assessment of Talent Practices, Perceived Organisational Support, Perceived Supervisor Support and Intention to Quit Questionnaires were administered.

The Human Capital Index (adapted version) of the Human Capital Institute (2008) was used to measure the perceived talent management practices of the organisation. The Index consisted of 45 items and measured 8 TMP namely Strategy, Talent Review Process, Staffing, Talent Acquisition, Talent Engagement, Talent Development, Talent Deployment, Performance Management and Talent Retention. Respondents were required to rate the current TMP in the organisation on a five-point scale ranging from "Poor (1)" to "Excellent (5)." This measure has proved to be a valid and reliable measure in various in various South African studies (see Barkhuizen, 2014a)

The Perceived Organizational Support Survey (SPOS) measures the employees' perception of the organization's attitude towards them (Shore \& Tetrick, 1991). The shortened version of Survey of Perceived Organizational Support (SPOS) consists of eight items that require the respondent to indicate the extent of their agreement with each statement on a seven-point Lickert-type scale ranging from strongly disagree (1) to strongly agree (7). The validity and reliability of the POS has been confirmed in various studies (Eisenberger, et al., 2002; Rhoades \& Eisenberger, 2002).

The Perceived Supervisor Support Questionnaire aims to assess the employees' perception that their supervisors value their contribution and care about their well-being. In order to assess this, the SPOS was adapted in this study to correlate with that used by Eisenberger, et al. (2002) and Shanock and Eisenberger (2006). The Survey of Perceived Supervisor Support that was used in this study consisted of eight items and required the respondents to score their answers on a seven point Lickert-type scale ranging from strongly disagree (1) to strongly agree (7). The validity and reliability of the POS has been established in various studies (see Eisenberger et al. 2002; Shanock and Eisenberger, 2006).

Three items were used to determine the employee's intent to quit the organization. Respondents were asked to rate the items on seven point Lickert scale ranging from strongly disagree (1) to strongly agree (7). Acceptable internal consistency of 0.91 was found for this instrument in the South African context (Kahumuza \& Schlechter, 2008).

The questionnaire was distributed electronically to the respondents. Participation was voluntary and privacy, confidentiality and anonymity of the participants were respected at all times. Ethical clearance was obtained prior to the execution of the study.

\section{DATA ANALYSES}

Data analysis was carried out using the SPSS Program (SPSS, 2009). The reliability and validity of the measuring instruments were determined by means of Cronbach alpha coefficients. Pearson product-moment correlation coefficient was used to specify the relationship between the variables. Multiple regression analysis was performed to test for the mediation/moderation relationships between the variables in this research.

\section{RESULTS}

Reliability analysis of the measurements was conducted prior to further analysis. Compared to the guidelines of $\alpha>$ 0,70 (Field, 2009), the alpha coefficients of the measurements in Table 2 are considered to be acceptable.

Table 1. Descriptive statistics and Alpha Coefficients of the Measurements

\begin{tabular}{l|c|c|c}
\hline \multicolumn{1}{c|}{ Scales } & Mean & SD & $\boldsymbol{\alpha}$ \\
\hline 1. POS & 5.38 & 1.17 & 0.86 \\
2. PSS & 5.78 & 1.10 & 0.87 \\
3. Intention to Quit & 3.58 & 1.75 & 0.88 \\
4. TMP & 2.99 & 0.904 & 0.96 \\
\hline
\end{tabular}




\section{Testing of Research Propositions}

Interrelationships Between POS, PSS, Intention to Quit and TMP

The main objective of this study was to establish the relationship between four variables: Perceived Organizational Support, Perceived Supervisor Support, Intention to Quit, and TMP. Pearson's product-moment correlation was used for this analysis. The results are reported in Table 2 below.

Table 2. Correlation Table between POS, PSS, Intention to Quit and TMP

\begin{tabular}{l|c|c|c}
\hline & POS & PSS & Intention to Quit \\
\hline POS & $-\bar{C}^{*+}$ & & \\
PSS & $0.72364^{++}$ & $-0.43 \overline{6} 10^{*^{+}}$ & - \\
Intention to Quit & $-0.56876^{*++}$ & $0.47096^{*^{+}}$ & -0.4771 * $^{+}$ \\
\hline
\end{tabular}

* Statistically significant: $p>0,01$

+ Practically significant correlation (medium effect): $r>0,30$

++ Practically significant correlation (large effect): $r>0,50$

The results in Table shows that Perceived Organisational Support is practically significantly related to Perceived Supervisor Support $\left(\mathrm{r}_{(\mathrm{df}=135 ; \mathrm{p}<0.001)}=0.724\right.$, large effect $)$, Intention to Quit $\left(\mathrm{r}_{(\mathrm{df}=135 ; \mathrm{p}<0.001)}=-0.569\right.$, large effect $)$ and Perceived TMP $\left(\mathrm{r}_{(\mathrm{df}}=135 ; \mathrm{p}<0.001\right)=0.640$, large effect $)$. Perceived Social support is practically significantly negatively related to Intention to Quit $\left(\mathrm{r}_{(\mathrm{df}}=135 ; \mathrm{p}<0.001\right)=-0.436$, medium effect) and practically significantly positively related to TMP $\left(\mathrm{r}_{(\mathrm{df}=135 ; \mathrm{p}<0.001)}=0.471\right.$, medium effect). TMP are practically significantly negatively related to employees' intention to quit $\left(\mathrm{r}_{(\mathrm{df}=135 ; \mathrm{p}<0.001)}=-0.477\right.$, medium effect $)$.

Based on the above results Propositions 1, 2, 3, 4, 6 and 7 are accepted.

\section{Multiple Regression Analysis}

Standard multiple regression was performed to determine whether perceived organizational support or perhaps perceived supervisor support mediates/moderates the relationship between TMP and intention to quit. The results of the multiple regression analysis with TMP and POS as independent variables, and the interaction between these variables (to test for mediating effects), and Intention to quit are reported in Table 3. (Note: All the independent variables were centred). In models 1 and 2, the effects of the independent variables were entered, while in the third model the interaction term was also entered.

Table 3. Regression Analysis -TMP, POS and Intention to Quit

\begin{tabular}{|c|c|c|c|c|c|c|c|c|c|}
\hline \multicolumn{2}{|r|}{ Model } & \multicolumn{2}{|c|}{ Unstandardized Coefficients } & \multirow{2}{*}{$\begin{array}{c}\begin{array}{c}\text { Standardized } \\
\text { Coefficients }\end{array} \\
\text { Beta } \\
\end{array}$} & \multirow[t]{2}{*}{$t$} & \multirow[t]{2}{*}{$p$} & \multirow[t]{2}{*}{$\boldsymbol{R}$} & \multirow[t]{2}{*}{$R^{2}$} & \multirow[t]{2}{*}{$\Delta \boldsymbol{R}^{2}$} \\
\hline & & B & SE & & & & & & \\
\hline 1 & \begin{tabular}{|l} 
Summary \\
(Constant) \\
TMP \\
\end{tabular} & $\begin{array}{c}11.611 \\
.195\end{array}$ & $\begin{array}{c}3.323 \\
.020\end{array}$ & .641 & $\begin{array}{l}3.494 \\
9.624\end{array}$ & $\begin{array}{l}.001 \\
.000\end{array}$ & .641 & .411 & .406 \\
\hline 2 & $\begin{array}{l}\text { Summary } \\
\text { (Constant) } \\
\text { TMP } \\
\text { POS } \\
\end{array}$ & $\begin{array}{l}25.825 \\
-.034 \\
-.263 \\
\end{array}$ & $\begin{array}{c}2.163 \\
.016 \\
.054 \\
\end{array}$ & $\begin{array}{l}-.191 \\
-.446 \\
\end{array}$ & $\begin{array}{l}11.941 \\
-2.085 \\
-4.863 \\
\end{array}$ & $\begin{array}{l}.000 \\
.039 \\
.000 \\
\end{array}$ & .587 & .345 & .335 \\
\hline 3 & $\begin{array}{l}\begin{array}{l}\text { Summary } \\
\text { (Constant) }\end{array} \\
\text { TMP } \\
\text { POS } \\
\text { TMP x POS }\end{array}$ & $\begin{array}{l}17.248 \\
.023 \\
-.054 \\
-.001\end{array}$ & $\begin{array}{l}7.392 \\
.050 \\
.181 \\
.001 \\
\end{array}$ & $\begin{array}{l}.129 \\
-.091 \\
-.618 \\
\end{array}$ & $\begin{array}{c}2.333 \\
.462 \\
-.297 \\
-1.213 \\
\end{array}$ & $\begin{array}{l}.021 \\
.644 \\
.767 \\
.227 \\
\end{array}$ & .594 & .352 & .338 \\
\hline
\end{tabular}

From Table 3 it is evident that Perceived TMP explains $41.1 \%$ of the variance in Intention to Quit TMP and POS combined explain $34.5 \%$ of the variance in Intention to Quit. However, adding the interaction of TMP and POS in the multiple regression analyses did not result in a significant increase in the explained percentage of 
variance in Intention to Quit. One can therefore conclude that POS does not mediate/moderate the relationship between TMP and Intention to Quit.

The results of the multiple regression analysis with TMP and PSS as independent variables, and the interaction between these variables (to test for mediating effects), and Intention to quit are reported in Table 4. (Note: All the independent variables were centred). In models 1 and 2, the effects of the independent variables were entered, while in the third model the interaction term was also entered.

Table 4. Regression Analysis -TMP, PSS and Intention to Quit

\begin{tabular}{|c|c|c|c|c|c|c|c|c|c|}
\hline \multicolumn{2}{|c|}{ Model } & \multicolumn{2}{|c|}{ Unstandardized Coefficients } & \multirow{2}{*}{$\begin{array}{c}\begin{array}{c}\text { Standardized } \\
\text { Coefficients }\end{array} \\
\text { Beta } \\
\end{array}$} & \multirow[t]{2}{*}{$t$} & \multirow[t]{2}{*}{$p$} & \multirow[t]{2}{*}{$R$} & \multirow[t]{2}{*}{$R^{2}$} & \multirow[t]{2}{*}{$\Delta R^{2}$} \\
\hline & & B & SE & & & & & & \\
\hline 1 & $\begin{array}{l}\text { Summary } \\
\text { (Constant) } \\
\text { TMP }\end{array}$ & $\begin{array}{c}-3075.477 \\
66.074\end{array}$ & $\begin{array}{c}590.866 \\
3.604\end{array}$ & .846 & $\begin{array}{l}-5.205 \\
18.335\end{array}$ & $\begin{array}{l}.000 \\
.000\end{array}$ & .846 & .717 & .714 \\
\hline 2 & $\begin{array}{l}\text { Summary } \\
\text { (Constant) } \\
\text { TMP } \\
\text { PSS }\end{array}$ & $\begin{array}{l}26.618 \\
-.063 \\
-.163\end{array}$ & $\begin{array}{c}2.464 \\
.015 \\
.050\end{array}$ & $\begin{array}{l}-.349 \\
-.272\end{array}$ & $\begin{array}{l}10.804 \\
-4.187 \\
-3.256\end{array}$ & $\begin{array}{l}.000 \\
.000 \\
.001\end{array}$ & .534 & .285 & .274 \\
\hline 3 & $\begin{array}{l}\text { Summary } \\
\text { (Constant) } \\
\text { TMP } \\
\text { PSS } \\
\text { TMP x PSS }\end{array}$ & $\begin{array}{l}17.990 \\
-.005 \\
.034 \\
-.001\end{array}$ & $\begin{array}{l}8.475 \\
.056 \\
.192 \\
.001\end{array}$ & $\begin{array}{l}-.027 \\
.057 \\
-.564\end{array}$ & $\begin{array}{c}2.123 \\
-.085 \\
.178 \\
-1.064\end{array}$ & $\begin{array}{l}.036 \\
.932 \\
.859 \\
.289\end{array}$ & .540 & .291 & .275 \\
\hline
\end{tabular}

From Table 4 it is evident that TMP explains $71.7 \%$ of the variance in Intention to Quit. TMP and POS combined explain $28.5 \%$ of the variance in Intention to Quit. However, adding the interaction of TMP and PSS in the multiple regression analyses did not result in a significant increase in the explained percentage of variance in Intention to Quit. One can therefore conclude that PSS does not mediate/moderate the relationship between TMP and Intention to Quit.

Based on the above results Propositions 5 and 8 are rejected.

\section{DISCUSSION}

Generation $\mathrm{Y}$ has become known for their professional mobility and constantly increasing turnover in organizations. As a result the retention of the best talent amongst Generation Y graduates will present employers with major challenges if organizations are not prepared to change and adapt to accommodate this new generation of employees. The purpose of this research was to determine whether there is a relationship between perceived talent management practices, organisational and supervisor support and Generation Y's intention to quit. The results are discussed in terms of the research propositions.

Hypothesis 1: A positive relationship exists between the employee's perception of the organization's TMP and POS.

The results of the Pearson correlations showed a practically significant positive relationship of a large effect between the organisation's Talent Management Practices and Perceived Organisational Support. This confirms Allen et al's (2003) finding that an employee's perception of supportive Human Resource practices (i.e. TMP) is an antecedent of POS. The employees' perception that the organization's practices are focused on optimising talent and that the organization is willing to invest in it will result in the perception that the organization values their contributions and cares about their general well-being.

Hypothesis 2: A positive relationship exists between the employee's perception of the organization's TMP and PSS. 
The results showed a practically significant correlation of a medium effect between the employee's perception of the organisation's TMP and Perceived Supervisor Support (PSS). This indicates that an increased conviction of the organization-wide application of TMP can be associated with an increased perception of Supervisor Support. These findings confirm Hutchison's (2007) research that employees' perception of the organization's actions has direct effects on their perception of support from their supervisors. One would expect this correlation to be present due to the unique implementation of TMP. One of the characteristics of the Talent Management paradigm is that all managers are responsible and accountable for the implementation of TM initiatives (Birchfield, 2002; Chuai, et al., 2008; Handfield-Jones, et al., 2001). The fact that supervisors act as agents for the organization and are the personification of TMP explains this relationship.

Hypothesis 3: A negative relationship exists between the employee's perception of the organization's TMP and his/her intention to quit.

The results showed a practically significant negative relationship of a medium effect between employees' perception of the organization's TMP and their intention to quit the organization. This indicates that high levels of perception of the application of TMP in an organization lead to low levels Intention to quit the organization. This affirms Allen et al. (2003) and Knight-Turvey and Neal's (2003) findings that supportive HR practices (i.e. TMP) that demonstrate an organization's willingness to invest in its talent, enhance talent retention.

Hypothesis 4: A negative relationship exists between the employee's perception of the organizational support and his/her intention to quit.

The results of the Pearson correlation analysis affirmed this proposition by demonstrating a strong practically significant negative relationship between Perceived Organizational Support (POS) and the employee's Intention to Quit, where high levels of Perceived Organizational Support is associated with a decreased intention to quit the organization. This confirms research which found a negative relationship between an employee's perception that the organization that an individual works for supports and cares for them (Perceived Organizational Support) and the individual's intention to quit (Allen, et al., 2003). This suggests that individuals with the perception that the organization they work for cares for them and supports them will be less inclined to seek alternative employment, as proposed by Eisenberger, Fasolo \& Davis-LaMastro in Allen et al. (2003). TMP that contribute to a perception that the organization that an employee works for cares and supports them will consequently decrease the employee's intention to leave the organization and therefore decrease the employee turnover rate.

Hypothesis 5: POS mediates the relationship between perceived TMP and the employee's intention to quit.

The multiple regression analysis demonstrated that the interaction of perceived TMP and POS did not result in a significant increase in the explained percentage of variance in Intention to Quit, though it is a non-significant effect of Intention to Quit. As a result one can conclude that POS does not mediate/moderate the relationship between perceived TMP and Intention to Quit. These findings contradict Allen et al.'s (2003) results which confirmed POS as a mediator of organizational supportive HR Practices (i.e. TMP) and intention to quit.

Hypothesis 6: A positive relationship exists between the POS and PSS.

The results of the Pearson product-moment analysis demonstrated a strong practically significant positive relationship between Perceived Organizational Support (POS) and Perceived Supervisor Support, where high levels of Perceived Organizational Support is associated with high levels of Perceived Supervisor Support (PSS). The results of this study affirm proposition 6 and also the findings of numerous other studies that established a positive relationship between PSS and POS (Allen, et al., 2003; Dawley, et al., 2008; DeConinck, 2010, Eisenberger, et al., 2002, Hutchison, 1997; Rhoades \& Eisenberger, 2002; Shanock \& Eisenberger, 2006; Zagenczyk, et al., 2010). The direction of the relationship is, however, still debated, since both directions have been confirmed in previous research. The degree to which the employees perceive that their supervisor cares for their well-being and supports them, consequently influences their perception that the organization cares for and supports them. It can therefore be deducted that a supervisor acts as an agent of the organization through the implementation of TMP and, as a result, becomes the personification of TMP. It can also be argued that the employees' perception that the organization 
values their contribution and cares about their well-being leads them to believe that their supervisors are favourably inclined towards them.

Hypothesis 7: A negative relationship exists between the employee's PSS and his/her intention to quit the organization.

The results of the Pearson correlation analysis affirmed this proposition by demonstrating a practically significant negative relationship of a medium effect between Intention to Quit and Perceived Supervisor Support (PSS). It can therefore be concluded that high levels of Perceived Supervisor Support can be related to a decreased Intention to Quit. The results confirm the research by Dawley et al. (2008) who found that when an employee's supervisor cares for and supports them, they will be less inclined to leave the organisation.

Hypothesis 8: PSS mediates the relationship between perceived talent management practice and the employee's intention to quit.

The multiple regression analysis demonstrated that PSS does not mediate/moderate the relationship between perceived TMP and Intention to Quit. This is an important finding, because no evidence in the relevant literature could be found to support this. The study of Allen et al. (2003) confirmed POS as a mediator of organizational supportive HR Practices and intention to quit. No study has examined the mediating characteristics of PSS in relation to perceived TMP.

The research makes important theoretical, psychometric and practical contributions. From a theoretical point of view, this research contributed to the body of knowledge regarding the perceptions of talent management practices amongst Generation $\mathrm{Y}$ employees and hence provided a quantitative method for assessing these perceptions in relation to other constructs. This is valuable as very little empirical research has been conducted on the topic of talent management among Generation Y employees in the global context. From a psychometric point of view, the results of this study contributed significantly to prove reliability of a fairly new instrument, The Human Capital Institute (HCI) Assessment of Talent Practices. From a practical point of view, the research provides a framework for management to understand that perceptions regarding talent practices and support influences employee's intent to leave an organization. A focus on implementing TMP in such a way that it sways Generation Y's perceptions of TMP can hold significant benefits in terms of talent retention.

\section{LIMITATIONS}

The research had some limitations. First a convenience sample was used in this study which means that the results of the research cannot be generalised to other generations or organisations. For future research it is recommended that the sample size should be expanded to include other generations and organisations with the purpose of generalising findings. Another limitation is the sample size, especially with regard to the distribution of demographic groups, which had limitations in terms of the findings applied to the total population. Finally, in terms of the research design, future studies should focus on longitudinal designs where inferences regarding cause and effect could be made.

\section{RECOMMENDATIONS}

Based on the results of the research it is recommended that the five-point Likert-type response scale used in the HCI should be further refined to improve the reliability and validity of responses. Due to the complexity of the issue at hand, the depth of the questionnaire and the fact that the questionnaire was administered at all organizational levels, it is suggested that at selected items, a "do not know" option should be provided. This could be necessary where respondents, due to a specific demographic variable (such as job category or organizational level), will not have sufficient information to assess the respective talent management practice sufficiently. At lower organizational levels it is possible that respondents could have no insights into organizational strategy or the alignment of it with compensation. In addition, further research should be undertaken where the construct validity of the TMP questionnaire is analysed with a larger sample that allows factor analysis. 


\section{CONCLUSION}

In conclusion, the study of talent management and, specifically, Generation Y's perceptions regarding this phenomenon is still a relatively new field of study and many gaps exist in the body of knowledge. Talent management is an encompassing, multifaceted construct with a myriad of perceptions that influence its effectiveness. It holds the potential to influence talent retention amongst Generation Y employees. The findings of this study not only provide valuable insights into the theory of talent management and its related perceptions and Generation Y's intention to leave but also provided insight into the effective management of Generation Y talent.

\section{AUTHOR INFORMATION}

Liesel Du Plessis was a Masters student at the Department of Human Resource Management, University of Pretoria. She is currently employed as a Human Resource Manager in Dubai, United Arabian Emirates.

Nicolene Barkhuizen is a Full Professor Research of the Faculty of Commerce and Administration, North-West University. She is also the leader of the talent management research programme at North-West University which is currently the front-runner in talent management research in Southern Africa. Nicolene has published extensively in this field.

Karel Stanz is an Associate Professor and Head of the Department of Human Resource Management, University of Pretoria. He serves on several professional bodies in the field of Industrial Psychology and Human Resource Management.

Nico Schutte is an Associate Professor at the Department of Public Administration, North-West University. He has published extensively in the field of strategic leadership and talent management. Nico has also been the CEO of various consulting companies specialising in leadership development and coaching.

\section{REFERENCES}

Allen, D.G., Shore, L.M. \& Griffeth, R.W. (2003). The Role of Perceived Organizational Support and Supportive Human Resource Practices in the Turnover Process. Journal of Management, 29(1), 99-118.

Armstrong-Stassen, M., \& Ursel, N.D. (2009). Perceived organizational support, career satisfaction, and the retention of older workers. Journal of Occupational and Organizational Psychology, 82, 201-220.

Ashton, C. \& Morton, L. (2005). Managing talent for competitive advantage. Strategic HR Review , 4(5), 28-31.

Barkhuizen, E. N. (2014a). Project talent management. In Y. Du Plessis, Y. (Ed.), Project management: A behavioural perspective: Theoretical principles, advanced practices and cases. Pearson Education, (Chapter 13, pp. 370-408, ISBN 97817758495 1)

Barkhuizen, E.N. (2014b). How relevant is Talent Management in Local Government Institutions? Mediterranean Journal of Social Sciences, 5(20), 2223-2230.

Barkhuizen, E.N., \& Stanz, K.J. (2010). Linking organisational energy and individual well-being: The Influence of Leader's Talent Mindset. Paper published in the peer reviewed conference proceedings of the $12^{\text {th }}$ Annual Conference of Global Business and Technology Association, Kruger National Park, South Africa, 5-9 July, pp. 50- 57, Gbata, USA

Bhatnagar, J. (2008). Managing capabilities for talent engagement and pipeline development. Industrial and Commercial Training , 40(1), 19-28.

Birchfield, D. (2002, April). Talent Attack. Management, 22-26.

Bassett, B. (2008). Working With Generation Y. Office PRO, 16-19.

Cantrell, S., \& Benton, J.M. (2007). The five essential practices of a talent multiplier. Business Strategy Series , 8(5), 358-364.

Cappelli, P. (2008). Talent Management for the Twenty-First Century. Harvard Business Review , 1-9.

Chew, Y.T \& Wong S.K. (2008). Effects of Career Mentoring Experience and Perceived Organizational Support on Employee Commitment and Intentions to Leave: A study among Hotel Workers in Malaysia. International Journal of Management , 2(4), 692-700.

Dawley, D.D., Andrews, M.C., \& Bucklew, N.S. (2008). Mentoring, supervisor support, and perceived organizationl 
support: what matters most? Leadership \& Organization Development Journal , 29(3), 235-247.

DeConinck, J.B. (2010). The effect of organizational justice, perceived organizational support, and perceived supervisor support on marketing employees' level of trust. Journal of Business Research, 63(12), 13491355

DeConinck, J.B. \& Johnson, J.T. (2009). The effects of Perceived Supervisor Support, Perceived Organizational Support, and Organizational Justice on Turnover Among Salespeople. Journal of Personal Selling \& Sales Management , XXIX (4), 333-350.

Eisenberger, R., Singlhamber, F., Vandenberghe, C., Sucharski, I.L., \& Rhoades, L. (2002). Perceived Supervisor Support: Contributions to Perceived Organization Support and Employee Retention. Journal of Applied Psychology, 87(3), 565-573.

Field, A. 2009. Discovering statistics using SPSS (3rd edn). London: Sage.

Galagan, P. (2008, May). Talent Management. $T \& D, 40-44$.

Gentry, W.A., Kuhnert, K.W., Mondore, S.P. \& Page, E.E. (2007). The influence of supervisory-support climate and unemployment rate on part-time employee retention. Journal of Management Development, 26 (10), 10051022.

Guthridge, M., Komm, A.B., \& Lawson, E. (2008). Making talent a strategic priority. The McKinsey Quaterly, 159.

Handfield-Jones, H., Michaels, E., \& Axelrod, B. (2001, November/December). Talent Management - A critical part of every leader's job. Ivey Business Journal , 53-58.

Harris, R.B., Harris, K.J., \& Harvey, P. (2007). A Test of Competing Models of the Relationships Among Perceptions of Organizational Politics, Percieved Organizational Support and Individual Outcomes. The Journal of Social Psychology, 147 (6), 631-655.

Hui, C., Wong, A, \& Tjosvold, D. (2007). Turnover intention and performance in China: The role of positive affectivity, Chinese values, percieved organizational support and constructive controversy. Journal of Occupational and Organizational Psychology, 80, 735-751.

Human Capital Institute Africa and Hewitt's Human Capital Consulting (2008). The State of Talent Management: Today's Challenges, Tomorrow's Opportunities. Human Capital Leadership Excellence eJournal , 1 (10).

Human Capital Institute (2008). Securing South Africa's Talent Base. Human Capital Leadership Excellence eJournal , 1(9), 1-33

Human Captial Institute and Vurv Technology (2008). The Role of HR in the Age of Talent. Human Capital Leadership Excellence eJournal , 1(6), 1-33.

Hutchison, S. (1997). A Path Model of Perceived Organizational Support. Journal of SOcial Behavior and Personality, 12 (1), 159-174.

Jawahar, I.M., \&Hemmasi, P. (2006). Perceived organizational support for women's advancement and turnover intentions. Women in Management Review , 21 (8), 643-661.

Knight-Turvey, N., \& Neal, A. (2003). High Commitment' human resource practices, affective organisational commitment, and employee leel outcomes: The role o perceived organisational support. Australian Journal of Psychology, 134.

Loi, R, Hang-yue, N., \& Foley, S. (2006). Linking employees' justice perceptions to organizational commitment and intention to leave: The mediating role of perceived organizational support. Journal of Occupational and Organizational Psychology, 79, 101-120.

Marah, T., \& Leigh-Ann, M. (2008). The war for talent: Fact or Fiction? Retrieved

May 7, 2010, from Human Capital Review: http://www.humancapitalreview.org/content/default.asp?Article_ID=91

McCauley, C. \& Wakefield, M. (2006, Winter). Talent Management in the 21st Century: Help Your Company Find, Develop, and Keep its Strongest Workers. Journal for Quality and Participation, 4-7.

Michaels, E.G. (1999). The war for talent, Human Resource Planning; 22 (4), 8-10.

Morgan, H.J. (2008). I hired you, you're perfect...now stay! Business Strategy Series , 9 (3), 119-125.

Nunnally, J.C., \& Bernstein, I.H. (1994). Psychometric theory ( $3^{\text {rd }}$ ed.). New York: McGraw-Hill.

O'Malley, S. (2006, November 20). Attracting and Retaining Generation Y Employees. Insurance Advocate, 27-30.

Pathbreakers (1996, November). Social Exchange Theory. Retrieved May 15, 2010, from University of Washington: http://www.washington.edu/research/pathbreakers/1978a.html

Pillay, P., Subban, M., \& Qwabe, B. (2008). Talent Management - "Putting the right people in the right jobs". Journal of Public Administration , 43 (3.1), 308-323.

PricewaterhouseCoopers. (2008). Managing Tomorrow's People: The future of work to 2020. Retrieved June 30, 
2010, from http://www.pwc.com/managingpeople2020

Reindl, R. (2007, February). Growing Talent at Edwards Lifesciences. Training \& Development , 38-41.

Rhoades, L., \& Eisenberger, R. (2002). Perceived Organizational Support: A Review of the Literature. Journal of Applied Psychology, 87 (4), 698-714.

Riggle, R.J., Edmondson, D.R, \& Hansen, J.D. (2009). A meta-analysis of the relaitonship between perceived organizational support and job outcomes: 20 years of research. Journal of Business Research ,62, 10271030 .

Rogelberg, S.G., \& Luong, A. (1998). Nonresponse to mailed surveys: A review and guide. Current Directions in Psychological Science, 7, 60-65.

Shanock, L.R., \& Eisenberger, R. (2006). When Supervisors Feel Supported: Relationships with Subordinates' Percieved Supervisor Support, Percieved Organizational Support, and Performance. Journal of Applied Psychology, 91 (3), 689-695.

Sharma, R. \& Bhatnagar, J. (2009). Talent management - competency development: key to global leadership. Industrial and Commercial training , 41 (3), 118-132.

Shore, L.M. \& Tetrick, L.E. (1991). A Construct Validity Study of the Survey of Perceived Organizational Support. Journal of Applied Psychology, 76 (5), 637-643.

SPSS Inc. (2013). SPSS 12.0 for Windows. Chicago, IL: Author.

Theron, M., Barkhuizen, E.N., \& Du Plessis, Y. (2014). Managing the academic talent void: Investigating factors in academic turnover and retention in South Africa. South African Journal of Industrial Psychology, 40(1), $1-14$.

Workforce Management (2007). A Framework for Talent Management. Workforce Management, 86 (12), 7.

Zagenczyk, T.J., Scott, K.D., Gibney, R., Murrell, A.J. \& Thatcher, J.B. (2010). Social Influence and Perceived Organizational Support: A Social networks analysis. Organizational Behavior and Human Decision Processes, 111, 127-138. 


\section{NOTES}

